\title{
Should Utility-Reducing Media Advertising be Taxed?
}

Kind, Hans Jarle; Köthenbürger, Marko; Schjelderup, Guttorm

Publication date:

2009

Document version

Publisher's PDF, also known as Version of record

Citation for published version (APA)

Kind, H. J., Köthenbürger, M., \& Schjelderup, G. (2009). Should Utility-Reducing Media Advertising be Taxed?. http://www.cesifo-group.de/portal/page/portal/ifoHome/b-publ/b3publwp/_wp_by_number?p_number=2589 


\title{
Should Utility-Reducing Media Advertising be Taxed?
}

\author{
HANS JARLE KIND \\ MARKO KOETHENBUERGER \\ GUTTORM SCHJELDERUP
}

CESIFO WORKING PAPER NO. 2589

CATEGORY 1: PuBliC FINANCE

MARCH 2009
An electronic version of the paper may be downloaded
- from the SSRN website:
www.SSRN.com
- from the RePEc website:
- from the CESifo website:
www.RePEc.org
www.CESifo-group.org/wp




\title{
Should Utility-Reducing Media Advertising be Taxed?
}

\begin{abstract}
Empirical evidence suggests that people dislike ads in media products like TV programs. In such situations standard economic theory prescribes that the advertising volume can be optimally reduced by levying a tax on ads. However, making use of recent advances in the theory of Industrial Organization and two-sided markets we show that taxing ads may be counterproductive. In particular, we identify a number of situations in which ad-adverse consumers are negatively affected by the tax, and we even show that the tax may lead to higher ad volumes. This unorthodox reaction to a tax may arise when consumers significantly dislike ads, i.e. in situations where traditional arguments for corrective taxes are strongest.
\end{abstract}

JEL Code: D4, D43, H21, H22, L13.

Keywords: two-sided markets, media market, pricing strategy, ad-tax.

Hans Jarle Kind

Norwegian School of Economics and

Business Administration

Helleveien 30

5045 Bergen

Norway

hans.kind@nhh.no
Marko Koethenbuerger

Department of Economics

University of Copenhagen

Studiestraede 6

1455 Copenhagen

Denmark

marko.koethenbuerger@econ.ku.dk

Guttorm Schjelderup

Norwegian School of Economics and Business Administration

Helleveien 30

5045 Bergen

Norway

guttorm.schjelderup@nhh.no 


\section{Introduction}

Media industries such as radio, TV, internet, newspapers, and magazines are major drivers in popular culture, and they take up the lion's share of peoples' leisure time. ${ }^{1}$ It is also a fact that most media firms rely on advertising to partially of fully finance their activities. However, empirical evidence suggests that people dislike ads in media products, at least on the margin, and worries have been raised over possible excessive advertising in e.g. TV channels. ${ }^{2}$ This has lead European countries to restrict the amount of TV commercials, and for a limited period of time some US states imposed a tax on advertising in printed media. ${ }^{3} \mathrm{~A}$ tax on ads has also been voiced in New Zealand (Allen et al., 2002) based on a nuisance argument. It is surprising given the importance media products play in our lives that there exists no formal analysis of pigouvian taxes on advertising. This is the topic of this paper.

The nuisance cost of advertising is likely to depend on the type of media products in which the advertising appears. One may for instance argue that readers relatively easily can avoid ads in newspapers simply by skipping pages, whilst program interruption on TV is more serious. This indicates that there is a relatively strong negative correlation between the advertising volume in a TV channel and the consumers' willingness to pay for watching it. The fact that commercial TV channels historically nonetheless have relied almost exclusively on advertising rev-

\footnotetext{
${ }^{1}$ The average American watches over four hours of TV per day and the average European watches closed to 3 hours and thirty minutes. See Anderson and Gabszewicz (2006) for further empirical documentation of media usage.

${ }^{2}$ It is well documented that viewers try to avoid advertising breaks on TV, see Moriarty and Everett (1994), Danaher (1995), and Wilbur (2008). For printed newspapers there are some indications that the extent to which people consider commercials as bad varies across countries (Gabszewicz et al., 2004).

${ }^{3}$ See ANA (2005) and the webpage by the American Advertising Federation (AAF): http://www.aaf.org/ -> government affairs.
} 
enue is presumably due to technological reasons; until recently it was difficult for TV channels to charge the viewers directly. However, this has changed with the advent of digitalization of TV signals. Not surprisingly, we have therefore observed a process where TV channels earn an increasingly large share of their revenue directly from the audience. ${ }^{4}$ TV channels as well as newspapers and magazines thus operate in what is commonly described as two-sided markets - their business models reflect the fact that they depend on revenue from both the consumer market and the advertising market. ${ }^{5}$

Standard economic theory prescribes that if advertising is disliked by the audience (negative externality), the advertising volume can be optimally reduced by levying a tax that reflects the nuisance cost of ads. Thereby the government is able to raise public tax revenue and correct for market failures with one and the same instrument. This insight certainly raises the question of whether it would be a good idea to replace the European system of quantity regulation on TV ads with corrective revenue-raising taxes. However, we do not focus on this specific issue. Instead we analyze more generally the effects of taxing ads in media industries that operate in two-sided markets.

The questions we ask are how a tax on ads changes media firms' market behavior, to what extent they reduce the ad volume, and how the media consumers are affected. We find that the traditional recommendation of imposing a tax on a good that causes a negative externality (utility-reducing ads) does not necessarily alleviate the negative externality. Rather it may actually aggravate it. In particular, we

\footnotetext{
${ }^{4}$ In the UK, for instance, TV channels made $£ 2$ bn in revenues from subscriptions in 2000 , far below the $£ 3.6$ bn in advertising revenue. In 2004, the revenues from subscription were $£ 3.3 \mathrm{bn}$ while the revenues from advertising were $£ 3.2 \mathrm{bn}$. See Ofcom (2005): 'The communication market 2005', section 1.4.3 at http://www.ofcom.org.uk/research/cm/cm05/overview05/finance/.

${ }^{5}$ Evans (2003) defines a two-sided market as one where we have (a) two distinct groups of customers, (b) positive network externalities (at least from one of the customer groups to the other), and (c) an intermediary that internalizes the externalities between the groups. See Rochet and Tirole (2006) for a more formal definition.
} 
identify a number of situations in which ad-adverse consumers are negatively affected by the tax, and we even show that the tax may lead to higher ad volumes. This unorthodox reaction to a tax may arise when consumers significantly dislike ads, i.e. in situations where the traditional arguments for corrective taxes are strongest.

It is only recently that firm behavior in two-sided markets has been formally analyzed - see for instance Caillaud and Jullien (2001, 2003), Armstrong (2006) and the review by Rochet and Tirole (2006). The focus of these contributions is how the two-sidedness of markets influences the pricing decision of firms. The effects of taxation are masked out in these papers. Kind et al. (2008) discuss the issue of taxation in two-sided markets but do not consider a tax on ads. Allen et al. (2002) consider a tax on advertising, but resort to a one-sided market structure. ${ }^{6}$

The paper proceeds as follows: Section 2 introduces the model of a two-sided media market, followed by an analysis of the effects of ad taxes in section 3. Section 4 summarizes the results and offers some concluding remarks.

\section{$2 \quad$ The model}

We consider a firm which sells a media product - which for simplicity we call newspapers $(\operatorname{good} N)$ - to consumers at price $p^{N}$ and ad space (good $A$ ) to producers at price $p^{A}$. Let $n$ and $a$ denote the respective quantities of the two goods. Both newspaper readers and advertisers are price takers, with inverse demand functions being downward-sloping in own quantity; $p_{n}^{N} \equiv \partial p^{N} / \partial n<0 ; p_{a}^{A} \equiv \partial p^{A} / \partial a<0$. In the sequel we further assume:

Assumption 1: $p_{n}^{A}(a, n)>0$ and $p_{a}^{N}(a, n)<0$.

With $\partial p^{A} / \partial n \equiv p_{n}^{A}(a, n)>0$ we have made the reasonable assumption that the willingness to pay for an ad is increasing in the number of newspaper readers, while

\footnotetext{
${ }^{6}$ See Fullerton and Metcalf, 2002 for a survey.
} 
$p_{a}^{N}(a, n) \equiv p_{a}^{N}<0$ means that the readers' willingness to pay for the newspaper is decreasing in the ad-level. The latter implies that the audience is ad-averse. ${ }^{7}$

Note that with Assumption 1 we cannot consider advertising and newspapers as complements in the usual sense, where a price reduction of one good leads to more sales of both goods. On the contrary, if the media firm reduces the price of advertising in order to sell more of that good, it will have to accept lower sales of the newspaper, other things being equal.

An ad-valorem tax $(t)$ is levied on ads, which implies that the newspaper receives the net price $p^{A} /(1+t)$ per advertisement. The tax rate $t$ may deviate from the general VAT rate, which for simplicity we set equal to zero. The profit level of the newspaper is given by

$$
\Pi=\frac{p^{A}(a, n) a}{1+t}+p^{N}(a, n) n-k(a, n),
$$

where $k(a, n)$ is the cost function, with $k_{i} \geq 0(i=a, n)$ and $k_{i j} \gtreqless 0(i \neq j){ }^{8}$

The media firm maximizes profit with respect to sales of newspapers and advertising space. We presuppose that the second-order conditions for profit maximization hold; $\Pi_{a a}<0, \Pi_{n n}<0$, and $H \equiv \Pi_{a a} \Pi_{n n}-\Pi_{a n}^{2}>0$.

From (1) we find that the first-order condition for the newspaper's advertising volume $\left(\Pi_{a}=0\right)$ reads

$$
\underbrace{\frac{p^{A}+p_{a}^{A} a}{1+t}}_{\equiv M R_{a}}=\underbrace{k_{a}-p_{a}^{N} n}_{\equiv P M C_{a}} .
$$

The left-hand side of equation (2) measures the marginal revenue on the advertising side of the market of selling ads $\left(M R_{a}\right)$, and this term should be set equal to marginal cost $\left(k_{a}\right)$ in a standard one-sided market. However, a one-unit increase in

\footnotetext{
${ }^{7}$ All the equations that follow go through independently of the sign of $p_{a}^{N}$.

${ }^{8}$ Intuitively, one might expect that the marginal cost of printed newspapers is increasing in the ad-volume, and vice versa (so that $k_{a n}>0$ ). However, there may also exist some cost synergies, which means that $k_{a n}<0$. Since our theoretical results go through in either case, we leave the sign of $k_{a n}$ unspecified.
} 
the ad-level means that the willingness to pay for the newspaper falls by $p_{a}^{N}$ units. With $n$ newspaper readers, this represents a loss equal to $p_{a}^{N} n$ for the media firm. We may therefore interpret the sum of the actual marginal costs $k_{a}$ and the externality term $-p_{a}^{N} n>0$ as the newspaper's perceived marginal costs of advertising $\left(P M C_{a}\right)$, that is, $P M C_{a} \equiv k_{a}-p_{a}^{N} n$. Equation (2) simply says that these perceived marginal costs are equal to marginal revenue in optimum. Since $P M C_{a}>k_{a}$ if the newspaper readers dislike ads, the first-order condition implies that the media firm sells a lower ad-volume than what maximizes profits on the ad-side of the market.

Setting $\Pi_{n}=0$ we further find that

$$
\underbrace{p^{N}+p_{n}^{N} n}_{\equiv M R_{n}}=\underbrace{k_{n}-\frac{p_{n}^{A} a}{1+t}}_{\equiv P M C_{n}},
$$

which has a similar interpretation to that of equation (2): the marginal revenue on the newspaper side of the market $\left(M R_{n}\right)$ should be set equal to the perceived marginal costs of selling a newspaper $\left(P M C_{n}\right)$. These perceived costs will be smaller than the actual marginal costs $\left(P M C_{n}<k_{n}\right)$ if a larger newspaper circulation increases the willingness to pay for ads. This is captured by the term $p_{n}^{A} a /(1+t) \geq$ 0 .

From (2) and (3) it follows that:

Lemma 1: Ceteris paribus, an increase in the ad-valorem tax on ads reduces the marginal revenue of selling ads $\left(\partial M R_{a} / \partial t<0\right)$ and increases the perceived marginal costs of selling newspapers $\left(\partial P M C_{n} / \partial t>0\right)$.

Note that $P M C_{n}<0$ if $k_{n}$ is sufficiently small compared to $p_{n}^{A} a$. This may for instance be the case with television and electronic newspapers, where marginal costs are approximately equal to zero. However, $P M C_{a}$ must certainly be positive if consumers dislike ads, even in cases where $k_{a}=0$.

The interrelationship between the two sides of the market is illustrated in Figure 1, where we have set marginal costs equal to zero. The left-hand side panel shows 
the profits in the reader market from selling newspapers, $\Pi^{N}=p^{N} n$, while the righthand panel shows the profits in the advertising market from selling ads, $\Pi^{A}=\frac{p^{A} a}{1+t}$. If the advertisers did not care about the number of readers and the readers did not care about the number of ads, the newspaper would maximize profit by setting $n^{*}=\arg \max \Pi^{N}$ and $a^{*}=\arg \max \Pi^{A}$. However, with $p_{n}^{A}>0$ and $p_{a}^{N}<0$ firstorder conditions (2) and (3) imply that, other things equal, we have $n^{\text {opt }}>n^{*}$ and $a^{o p t}<a^{*}$.
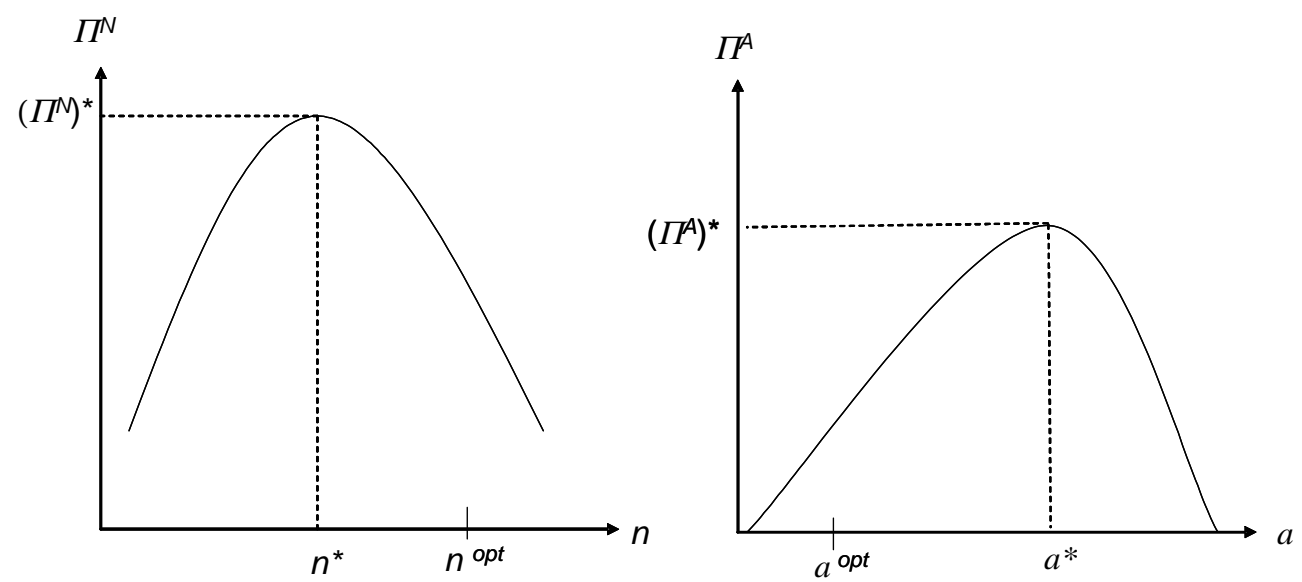

Figure 1: Implications of the first-order conditions.

\section{Tax responses}

Standard welfare economics tells us to tax a good which imposes a negative externality. ${ }^{9}$ By assuming that $p_{a}^{N}<0$ we have thus tilted the model such that taxation of ads at the outset should have a positive welfare effect. Below, we show that this does not necessarily hold in a two-sided market.

First-order conditions (2) and (3) make it clear that equilibrium prices and quantities on both sides of the market depend on the tax rate on ads. Differentiating $p^{A}=p^{A}(a(t), n(t))$ and $p^{N}=p^{N}(a(t), n(t))$ with respect to $t$ we find that the price

${ }^{9}$ If $p_{n}^{A}$ and/or $p_{a}^{N}$ are different from zero we have externalities between the customer groups. The reason is that price-taking producers and consumers do not take into account the effect of their actions on the demand in either side of the market. 
changes subsequent to a tax increase are given by

$$
\frac{d p^{A}}{d t}=p_{a}^{A} \frac{d a}{d t}+p_{n}^{A} \frac{d n}{d t} \quad \text { and } \quad \frac{d p^{N}}{d t}=p_{n}^{N} \frac{d n}{d t}+p_{a}^{N} \frac{d a}{d t}
$$

By totally differentiating first order conditions (2) and (3) we further have

$$
\frac{d a}{d t}=\frac{1}{H(1+t)}\left[M R_{a} \Pi_{n n}+\frac{p_{n}^{A} a}{1+t}\left(-\Pi_{a n}\right)\right]
$$

and

$$
\frac{d n}{d t}=\frac{1}{H(1+t)}\left[\frac{p_{n}^{A} a}{1+t} \Pi_{a a}+M R_{a}\left(-\Pi_{a n}\right)\right] .
$$

The sign of $\Pi_{a n} \equiv \partial^{2} \Pi /(\partial a \partial n)$ turns out to be of particular relevance for the tax analysis, and by using equations (1) - (3) we find

$$
\Pi_{a n}=p_{a}^{N}\left[1+\varepsilon_{n}\right]+p_{n}^{A}(1+t)^{-1}\left[1+\varepsilon_{a}\right]-k_{a n},
$$

where $\varepsilon_{n} \equiv \frac{n}{p_{a}^{N}} \frac{\partial p_{a}^{N}}{\partial n}$ and $\varepsilon_{a} \equiv \frac{a}{p_{n}^{A}} \frac{\partial p_{n}^{A}}{\partial a}$.

The cross derivative $\Pi_{a n}$ measures how the marginal profitability of selling newspapers,$\Pi_{n}$, changes if the advertising volume increases. One might think that $\Pi_{a n}$ is negative, given the assumption that the willingness to pay for the newspaper is decreasing in the advertising volume $\left(p_{a}^{N}<0\right)$. However, if the elasticity of $p_{a}^{N}$ with respect to $n$ is smaller than minus one $\left(\varepsilon_{n}<-1\right)$, the first term in $(7)$ is positive. The interpretation of the second term in (7) is similar; this term is positive for $p_{n}^{A}>0$ if $\varepsilon_{a}>-1$. Clearly, we might therefore have $\Pi_{a n}>0$, and we are not aware of any empirical studies which can help us determine the sign. We shall therefore consider both the case $\Pi_{a n} \geq 0$ and $\Pi_{a n}<0$.

\section{A tax on ads when $\Pi_{a n} \geq 0$}

When $\Pi_{a n} \geq 0$, the marginal profitability of newspaper sales is increasing in the ad-volume. We shall start this section by assuming that $\Pi_{a n}=0$. In this case an increase in $t$ unambiguously leads to a lower advertising volume $(d a / d t<0)$, since 
the media firm's marginal revenue of selling ads falls. Formally, this can be seen from equation (5), which now simplifies to

$$
\left.\frac{d a}{d t}\right|_{\Pi_{a n}=0}=\frac{\Pi_{n n}}{H(1+t)} M R_{a}<0 .
$$

By taxing ads, the government is thus able to reduce the ad volume in the newspaper. Other things equal, this makes the newspaper more attractive for the consumers. However, this does not imply that output of newspapers increases. On the contrary, from equation (6) we find

$$
\left.\frac{d n}{d t}\right|_{\Pi_{a n}=0}=\frac{\Pi_{a a}}{H(1+t)^{2}} p_{n}^{A} a<0 .
$$

The intuition for why $d n / d t<0$ is clear from Lemma 1: a higher tax rate on ads increases the perceived marginal cost of selling newspapers. ${ }^{10}$ Thus, it is optimal to reduce output.

The negative quantity effects of a higher tax on ads are magnified if $\Pi_{a n}>0$, since a smaller newspaper circulation then reduces the marginal profitability of selling ads and vice versa. This can be verified by noting that the last terms in the square bracket of (5) and (6) are negative when $\Pi_{a n}>0$. We can therefore state:

Proposition 1: Suppose that $\Pi_{a n} \geq 0$. A higher ad-valorem tax on ads reduces sales of both ads and newspapers.

Next, consider how an increase in $t$ affects the end-user prices on the two sides of the market. The direct effect of a smaller sale of newspapers is to increase the price of newspapers (since the demand curve is assumed to be downward-sloping). Additionally, the willingness to pay for newspapers increases since the ad-volume is reduced. From equation (4) we therefore find $d p^{N} / d t>0$.

\footnotetext{
${ }^{10}$ From (3) we have $k_{n}-P M C_{n}=\frac{p_{n}^{A} a}{1+t}>0$. Substituting for $\frac{p_{n}^{A} a}{1+t}$ into (9) we can write $\left.\frac{d n}{d t}\right|_{\Pi_{a n}=0}=\frac{\Pi_{a a}}{H(1+t)^{2}}\left(k_{n}-P M C_{n}\right)<0$.
} 
The effect on the price of ads is ambiguous. The own-price effect suggests that the price increases, while the fact that newspaper sales fall suggests a lower price. The net effect depends on which of these effects dominates, such that $d p^{A} / d t \lesseqgtr 0$.

We can state:

Proposition 2: Suppose that $\Pi_{a n} \geq 0$. A higher ad-valorem tax on ads increases the price of newspapers, while the effect on the price of ads is ambiguous.

Somewhat surprisingly, and in sharp contrast to results in one-sided markets, Proposition 2 shows that the end-user price of the more heavily taxed good might fall. The end-user price of the good where the tax rate is unchanged, on the other hand, increases.

\section{Monopoly vs. duopoly with $\Pi_{a n} \geq 0$}

Above we only considered a monopoly newspaper in order to make the general analysis tractable. To gain some extra insight and to show that the results survive under competition, we shall now illustrate the findings above in a simple duopoly model. Using the same media model as in Kind et al (2007), we assume that the consumers have the following utility function:

$$
U=\sum_{i=1}^{2} n_{i}-\left[(1-s) \sum_{i=1}^{2} \frac{n_{i}^{2}}{2}+s\left(\sum_{i=1}^{2} \frac{n_{i}}{2}\right)^{2}\right] ; i=1,2 .
$$

The variable $n_{i}$ in equation (10) denotes consumption of newspaper $i=1,2$, while the parameter $s \in[0,1]$ measures how differentiated the newspapers are; from the readers' point of view they are completely unrelated if $s=0$ (so that each newspaper behaves as a monopoly), while they are considered as perfect substitutes if $s=1$. More generally, the readers perceive the newspapers as closer substitutes the higher $s$ is. ${ }^{11}$

\footnotetext{
${ }^{11}$ The Shubik-Levitan (1980) formulation in equation (10) ensures that the parameter $s$ only
} 
Each consumer has to make a direct payment $p_{i}^{N} \geq 0$ per copy of newspaper $i$. Consistent with Assumption 1 we further presuppose that the newspaper readers are negatively affected by commercials. The willingness to pay for newspaper $i$ is consequently decreasing in its advertising level; $\partial p_{i}^{N} / \partial a_{i}=-\gamma$, where $\gamma$ is a positive parameter. The higher $\gamma$, the greater is the consumers' disutility of advertising. The consumer surplus from reading the newspapers is thus equal to

$$
C S=U-\sum_{i=1}^{2}\left(p_{i}^{N}+\gamma a_{i}\right) n_{i}
$$

Maximizing consumer surplus with respect to consumption of the two newspapers generates the inverse demand function

$$
p_{i}^{N}=1-(2-s) n_{i} / 2-\gamma a_{i}-s n_{j} / 2 \quad(i, j=1,2, i \neq j) .
$$

Consumer-good producers advertise in newspaper $i$ if the benefit of doing so is larger than the cost. A producer's gross gain from advertising in newspaper $i$ is naturally increasing in its advertising level $\left(a_{i}\right)$ and in the number of readers exposed to its advertising $\left(n_{i}\right)$. We make it simple by assuming that the gross gain equals $a_{i} n_{i}$. With a price per ad equal to $p_{i}^{A}$, the net gain from advertising is

$$
\pi=\left(\sum_{i=1}^{2} a_{i} n_{i}\right)-\left(\sum_{i=1}^{2} p_{i}^{A} a_{i}\right) .
$$

Without affecting the qualitative results, we assume that there is only one advertiser. Solving $\left\{a_{1}, a_{2}\right\}=\arg \max \pi$ subject to (11) we find that the inverse demand curve for ads in newspaper $i$ equals

$$
p_{i}^{A}=1-\frac{(2-s)\left(p_{i}^{N}+2 \gamma a_{i}\right)-s\left(p_{j}^{N}+2 \gamma a_{j}\right)}{2(1-s)} \quad(i, j=1,2 ; i \neq j) .
$$

The willingness to pay for an ad in newspaper $i$ is thus decreasing in its advertising volume $\left(\partial p_{i}^{A} / \partial a<0\right)$ and in the consumer price of the newspaper $\left(\partial p_{i}^{A} / \partial p_{i}^{N}<0\right)$.

captures product differentiation and not the size of the market. This is in contrast to the standard quadratic utility function, where one and the same parameter measures both product differentiation and market size. See Motta (2004) for details. 
The reason for the latter is that a higher newspaper price tends to reduce newspaper circulation, thereby making advertising less attractive. Since the two newspapers compete in the reader market if $s>0$, equation (13) further shows that the willingness to pay for ads in newspaper $i$ is increasing in the advertising level and price of newspaper $j$.

Analogously to equation (1), the profit level of newspaper $i$ equals

$$
\Pi_{i}=\frac{p_{i}^{A} a_{i}}{1+t}+p_{i}^{N} n_{i}-k\left(a_{i}, n_{i}\right)
$$

Since the purpose of this example is to illustrate the consequences of taxing ads when the marginal profitability of newspaper sales is increasing in the ad level $\left(\Pi_{a n} \equiv \frac{\partial^{2} \Pi_{i}}{\partial n_{i} \partial a_{i}}>0\right)$, we shall for simplicity set $k=0$. We then have

$$
\Pi_{a n}=\frac{1}{1+t}-\gamma>0
$$

The assumption that $k=0$ is not critical, as long as the costs are not so high as to make $\Pi_{a n}<0$.

Solving $\left\{a_{i}, n_{i}\right\}=\arg \max \Pi_{i}$ simultaneously for the two media firms, we find a unique symmetric equilibrium. Omitting subscripts, output of newspapers and advertising is given by

$$
n=\frac{2 \gamma(4-3 s)}{D_{1}} \text { and } a=\frac{4(1-\gamma(1+t))(1-s)}{D_{1}} .
$$

In the Appendix we show that the denominator $D_{1}$ is positive when the second-order conditions and the non-negativity constraints are satisfied.

For comparison between conventional markets (one-sided markets) and two-sided markets the following may now be noted:

Remark 1: Assume a one-sided market structure $\left(p_{n}^{A}=p_{a}^{N}=0\right)$. Prices, output, and welfare are then independent of the VAT rate if $k=0$.

The intuition for the results in Remark 1 is that ad-valorem taxes work as pure profit taxes in one-sided markets if marginal costs are zero $(k=0)$, making the 
firms' profit maximizing prices and outputs independent of $t$. This is true whether we have perfect or imperfect competition. If $k_{a}>0$, on the other hand, the firm's marginal costs would be increasing in the tax level, in which case we would have $d p_{n}^{A} / d t>0$ and $d a / d t<0$.

\subsection{Monopoly}

When analyzing the tax responses in a two-sided market structure, we confine ourselves to considering the consequences of a small tax increase from $t=0$. We start out by setting $s=0$, such that the newspapers are monopolies in each of their market segments. In the Appendix we show that non-negative prices require that $\gamma \in(1 / 3,1)$. If $\gamma \leq 1 / 3$, consumers have so little aversion against ads that the media firms prefer to give the newspapers away for free to the consumers. In this case their whole profit originates from the ad market. Conversely, if $\gamma \geq 1$, consumers have such a negative attitude towards ads that the media firm maximizes profits by setting $a_{i}=0$. In this case its entire revenue is derived from the reader market.

Differentiating (16) with respect to $t$ we find that the quantity changes subsequent to a tax increase from $t=0$ are given by

$$
\left.\frac{d a}{d t}\right|_{t=0}=-\frac{1+5 \gamma^{2}-2 \gamma}{D_{1}^{2}}<0 \text { and }\left.\frac{d n}{d t}\right|_{t=0}=-2 \frac{\gamma\left(1-\gamma^{2}\right)}{D_{1}^{2}}<0
$$

By inserting for (16) into (11) and (13) we further have

$$
\begin{aligned}
\left.\quad \frac{d p^{A}}{d t}\right|_{t=0} & =-\gamma \frac{2 \gamma-7 \gamma^{2}+1}{D_{1}^{2}}<0 \text { for } \gamma<\gamma^{*} \equiv(1+2 \sqrt{2}) / 7 \\
\text { and }\left.\frac{d p^{N}}{d t}\right|_{t=0} & =\gamma \frac{3\left(1+\gamma^{2}\right)-2 \gamma}{D_{1}^{2}}>0 .
\end{aligned}
$$

Figure 2 illustrates equations (17) and (18) graphically. Consistent with Proposition 1, sales of both advertising and newspapers fall subsequent to a higher tax. Note also that if $\gamma<\gamma^{*} \approx 0.55$, then the end-user price of newspapers, where the tax rate is unchanged, increases, while the end-user price of advertising, where the tax rate has increased, falls. This is consistent with Proposition 2. 
The reason why $d p^{A} /\left.d t\right|_{t=0}<0$ for $\gamma<\gamma^{*}$ is that if the readers do not care much about the ad-volume, the media firm will sell a large amount of newspaper copies in order to generate a high income from the ad-market. This incentive is significantly reduced if ads are taxed. Thus, there will be a big drop in newspaper sales. This reduces the willingness to pay for ads, leading to a fall in the ad price. Only for $\gamma>\gamma^{*}$ is the own-price effect so strong that the reduced supply of ad space increases the price of ads.
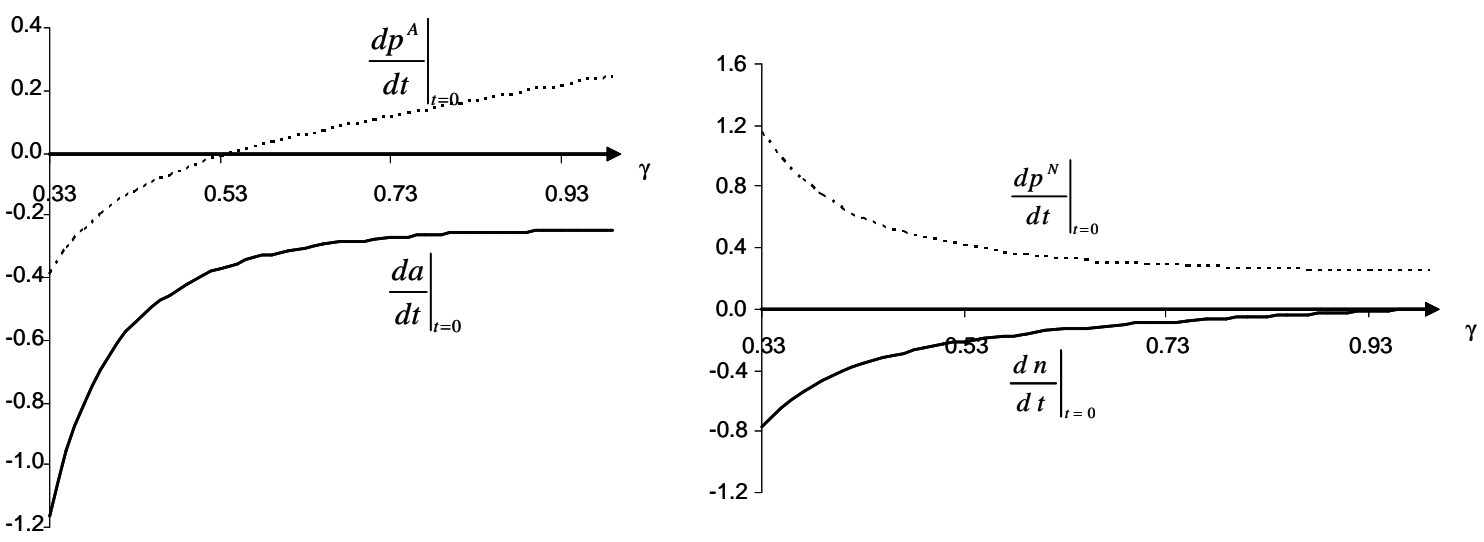

Figure 2: Price and quantity responses.

Figure 2 verifies that price and quantity responses to higher taxes in two-sided markets may differ qualitatively from those we find in one-sided market. A second deviation from standard results in one-sided markets, is that even a small tax on a good with negative externalities (advertising) may have negative welfare consequences. To see this, we define welfare in the usual way as the sum of consumer surplus, profit, and tax revenue $(T)$ :

$$
W=C S+2 \Pi+\pi+T
$$

where $T=\frac{t}{1+t}\left(2 p^{A} a\right)$.

From the envelope theorem it follows that the tax revenue of increasing the tax rate marginally from $t=0$ is equal to the profit losses of the media firms; $\left.\frac{d\left(\Pi_{1}+\Pi_{2}\right)}{d t}\right|_{t=0}=-\left.\frac{d T}{d t}\right|_{t=0}$. This means that $\left.\frac{d W}{d t}\right|_{t=0}=\left.\frac{d C S}{d t}\right|_{t=0}+\left.\frac{d \pi}{d t}\right|_{t=0}$. By using 
equations (11) and (13) we find the following simple expressions for consumer surplus and profit for the advertiser: ${ }^{12}$

$$
C S=n^{2} \text { and } \pi=2 \gamma a^{2}
$$

From this we immediately see that

$$
\left.\frac{d C S}{d t}\right|_{t=0}=\left.2 n \frac{d n}{d t}\right|_{t=0}<0 \text { and }\left.\frac{d \pi}{d t}\right|_{t=0}=\left.4 \gamma a \frac{d a}{d t}\right|_{t=0}<0 .
$$

It thus follows that for all $\gamma \in(1 / 3,1)$ we have

$$
\left.\frac{d W}{d t}\right|_{t=0}=-2 \frac{\gamma(1-\gamma)\left(1+7 \gamma^{2}\right)}{D_{1}^{3}}<0 .
$$

Even though advertising imposes a negative externality on the newspaper readers, a higher tax on ads consequently has a negative effect on consumer surplus and welfare. There are two reasons for this somewhat paradoxical result. First, a higher tax on advertising increases the perceived marginal costs of selling newspapers, as stated in Lemma 1. This effect is present independent of the sign of $\Pi_{a n}$. Second, if $\Pi_{a n}>0$ the lower output of newspapers reduces the marginal profitability of selling ads, which again reduces the marginal profitability of selling newspapers. In this sense a higher tax on ads leads to a vicious circle where output contractions of newspapers and ads mutually reinforce each other.

\subsection{Duopoly}

So far we have assumed that $s=0$, which means that each media firm has monopoly power in its own market segment. All the qualitative results above survive as long as the consumers perceive the media products as imperfect substitutes. In particular, the firms will use their market power to shift part of the tax burden over to the consumers and the advertisers if $s<1$ (contrary to what they would be able to do

\footnotetext{
${ }^{12}$ The equation $\pi=\gamma a^{2}$ might leave the counterintuitive impression that the advertiser's profit level is increasing in $\gamma$. However, this is not correct, since the ad volume is decreasing in the reader's disutility of ads. We consequently find $\frac{d \pi}{d \gamma}=-\frac{2(1-\gamma(1+t))(1+\gamma(1+t))^{3}}{N^{3}(1+t)^{-2}}<0$.
} 
in a one-sided market with $k=0$ ). The ability to do so is smaller the more fiercly the firms compete, though. This is most obvious if we use equation (16) and consider the consequences of a small tax increase from $t=0$ on output:

$$
\begin{aligned}
& \left.\frac{d n}{d t}\right|_{t=0}=-8(1-s) \frac{\gamma\left(1-\gamma^{2}\right)(4-3 s)}{D_{1}^{2}}<0 \\
& \left.\frac{d a}{d t}\right|_{t=0}=-4(1-s) \frac{4\left(1+5 \gamma^{2}-2 \gamma\right)(1-s)+3 s^{2} \gamma^{2}}{D_{1}^{2}}<0 .
\end{aligned}
$$

Equation (20) shows that sales of both newspapers and advertising space fall subsequent to an increase in $t$ as long as there is imperfect competition between the firms. However, as $s \rightarrow 1$ we have $d n / d t=d a / d t \rightarrow 0$. The reason for this is that the consumers perceive the newspapers as perfect substitutes at $s=1$, implying that the media firms have no market power. Then the advertising tax works as a pure surplus tax, just as in a one-sided market (with no distortionary effects). Thus, it is only in the limit case where the firms produce perfect substitutes that the consequences of a tax increase are the same in one-sided and two-sided markets.

Before ending this section, it is useful to analyze what happens to $p^{A}$ under duopoly if the government introduces a small tax on advertising. It turns out that the price effect is ambiguous also with (imperfect) competition between the media firms. This is illustrated on the left-hand side panel of Figure 3, which shows the combinations of $s$ and $\gamma$ where $d p^{A} / d t=0$. For $s=0$ the firms have monopoly power, in which case we have seen that each media firm will reduce the advertising price if $\gamma<\gamma^{*}=0.56$, and increase the advertising price if $\gamma>\gamma^{*}$. However, the media firms' ability to increase the advertising price subsequent to a tax increase is smaller the closer substitutes the media products are. This explains why the curve in the Figure is upward-sloping. Indeed, as we approach $s=1$ the media firms will have no ability to increase the advertising price.

The Figure indicates that there is a complex relationship between the extent of competition and the change in the advertising price as the tax increases. For a given value of $\gamma$ it might for instance be true that two monopolies prefer to increase the advertising price, while the opposite holds for two competing firms. This is 
illustrated on the right-hand side of Figure 3, where we have set $\gamma=6 / 10$. For $s \in[0,72)$ we have $d p^{A} /\left.d t\right|_{t=0}>0$, while $d p^{A} /\left.d t\right|_{t=0}<0$ for $s \in(0.72,1.0)$. Note also that in the limit $s=1$ we must have $d p^{A} /\left.d t\right|_{t=0}=0$, since the tax then works as a pure surplus tax.
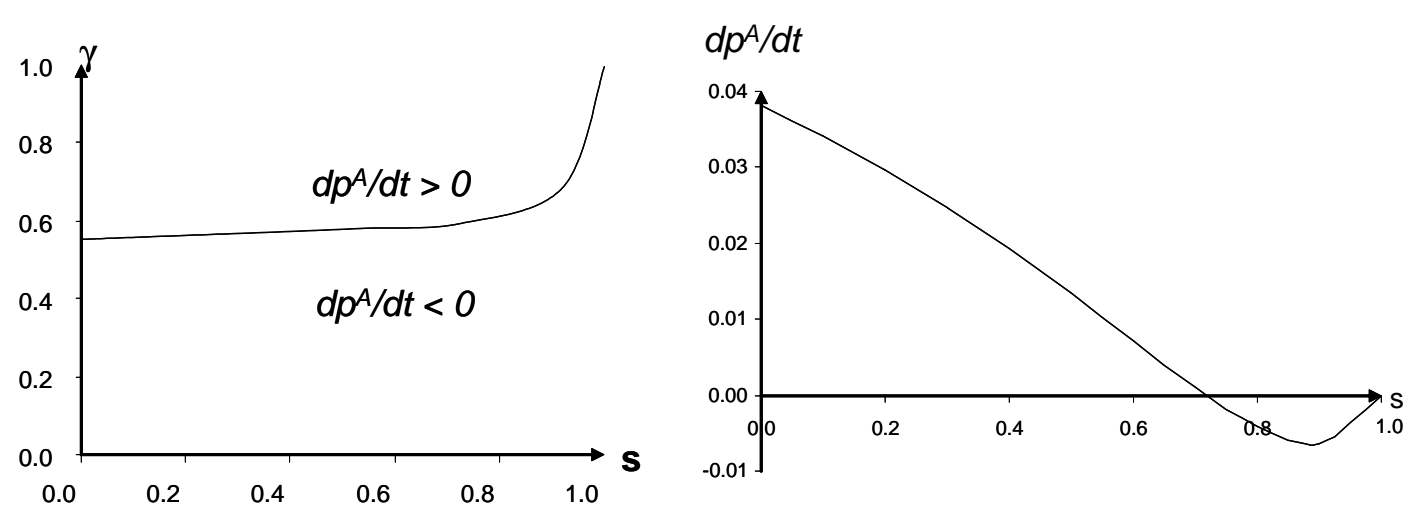

Figure 3: Tax responses and competition.

\section{A tax on ads when $\Pi_{a n}<0$}

When $\Pi_{a n}<0$, the marginal profitability of newspaper sales is decreasing in the advolume. Contrary to the results above, it is then not necessarily true that a higher ad-valorem tax on ads reduces sales on both sides of the market. It may actually be the case that output of either ads or newspapers increases. Equations (5) and (6), which for the sake of convenience we repeat here, make this clear:

$$
\begin{aligned}
& \frac{d a}{d t}=\frac{1}{H(1+t)}[\underbrace{M R_{a} \Pi_{n n}}_{-}+\underbrace{\frac{p_{n}^{A} a}{1+t}\left(-\Pi_{a n}\right)}_{+}] \\
& \frac{d n}{d t}=\frac{1}{H(1+t)}[\underbrace{\frac{p_{n}^{A} a}{1+t} \Pi_{a a}}_{-}+\underbrace{M R_{a}\left(-\Pi_{a n}\right)}_{+}]
\end{aligned}
$$

The first term in the square brackets of (21) is always negative, but the second term is positive if $\Pi_{a n}<0$. The total effect is thus ambiguous. However, in the Appendix we prove the following result: 
Proposition 3. Suppose $\Pi_{a n}<0$. A higher ad-valorem tax on ads reduces sales on one side of the market, and may increase sales on the other side. The following combinations are possible:

(i) $d a / d t \leq 0$ and $d n / d t \lessgtr 0$.

(ii) $d a / d t>0$ and $d n / d t<0$.

If sales of one good drop, the marginal profitability of selling the other good increases when $\Pi_{n a}<0$. This explains why output of the two goods may move in opposite directions, as stated in Proposition 3. Due to the ambiguity of the quantity effects, it is clear that also the price responses (4) are ambiguous.

The last part of Proposition 3 is surprising, as it states that the ad-volume may increase following a rise in the ad tax. We shall below demonstrate that this result occurs when the readers' disutility from ads is sufficiently high. We do this by looking at a simple example which encompasses both monopoly and duopoly.

\section{$7 \quad$ Monopoly vs. duopoly with $\Pi_{a n}<0$}

In Section 5 we showed that the media firms' possibility of shifting the tax burden over to consumers and advertisers is smaller the less differentiated the consumers perceive the media products to be (as measured by the parameter $s$ ). It can be shown that the effects of an increase in $s$ (reduced newspaper differentiation) are the same in the example we shall now look at. For simplicity we therefore set $s=0$. This means that we can simplify equation (11), which expresses consumer demand for the two media products, to

$$
p_{i}^{N}=1-\gamma a_{i}-n_{i} .
$$

We thus have a standard downward-sloping linear demand curve for newspapers, where the willingness to pay for a newspaper is decreasing in the ad volume if $\gamma>0$. For simplicity we further assume that we can linearize demand for ads around the 
equilibrium point to

$$
p_{i}^{A}=1-a_{i}+n_{i}-h a_{j}
$$

The willingness to pay for an ad is thus decreasing in the ad volume and increasing in the size of the readership. The inclusion of the parameter $h \in[0,1]$ in equation (23) is inspired by Godes et al (2008), and measures to what extent the two newspapers compete in the advertising market. If $h=0$ each newspaper has monopoly power in the advertising market, while they are perceived as perfect substitutes if $h=1$.

The media firms' profit functions are the same as in Example 1 (c.f. equation (12)), but to ensure that $\Pi_{a n}<0$ as simple as possible we specify the cost function as $k_{i}=a_{i} n_{i}+n_{i} / 2$. We now have

$$
\Pi_{a n}=-\frac{t(1+\gamma)+\gamma}{1+t}<0
$$

The newspapers solve $\left\{a_{i}, n_{i}\right\}=\arg \max \Pi_{i}$ simultaneously. Omitting subscripts, the first-order conditions for a symmetric equilibrium are given by

$$
a=(1+t) \frac{4-t-\gamma(1+t)}{2 D_{2}} \text { and } n=\frac{2-(1+t)(2 \gamma-h)}{2 D_{2}}
$$

The denominator $D_{2}$ is positive whenever the second-order conditions and nonnegativity constraints hold (see Appendix).

Before analyzing the consequences of a tax increase in this two-sided market, it is useful to note the following:

Remark 2: Assume that the markets are one-sided $\left(p_{n}^{A}=p_{a}^{N}=0\right)$. If $h=0$, prices, output and welfare are independent of the VAT rate. If $h>0$, then $d a_{i} / d t<$ 0 and $d n_{i} / d t>0$.

The results in Remark 2 are proved in the Appendix. If $h=0$ we have the same result as in Example 1: the VAT on ads works as a pure surplus tax, with no effect on output and prices. However, if $h>0$ the firms will compete in the advertising market, and this competition will be stronger the larger $h$ is. A higher value of $h$ therefore makes it optimal for the firms to reduce production of the $A$-good 
and increase production of the $N$-good, and more so the higher the VAT rate. Since the demand curves are downward-sloping, this further implies $d p^{A} / d t>0$ and $d p^{N} / d t<0$.

\subsection{Monopoly}

As in Section 5, we start out by considering the monopoly case. In the present case this amounts to setting $h=0$, and it can be shown that all non-negativity constraints and second-order conditions hold for $\gamma \in(0,1)$. From equation (25) we now have:

$$
\left.\frac{d n}{d t}\right|_{t=0}=-\frac{2-2 \gamma+\gamma^{2}}{D_{2}^{2}(\gamma+2)^{-1}}<0 \text { and }\left.\frac{d a}{d t}\right|_{t=0}=\frac{3 \gamma-2}{2 D_{2}^{2}(\gamma+2)^{-1}} \lesseqgtr 0 .
$$

The reason why newspaper sales fall, is that a higher tax on ads increases the perceived marginal costs of selling newspapers (c.f. Lemma 1). The drop in newspaper sales in turn raises the marginal profitability of selling ads, and (26) shows that $d a / d t>0$ if $\gamma>2 / 3$. It is thus when the readers' disutility from ads is sufficiently large that a higher tax on ads leads to more advertising. This is illustrated in Figure 4, which also shows that the advertising price (inclusive of taxes) falls when $t$ increases. This is due to the fact that the willingness to pay for ads is reduced because the newspaper circulation falls $(d n / d t<0)$.

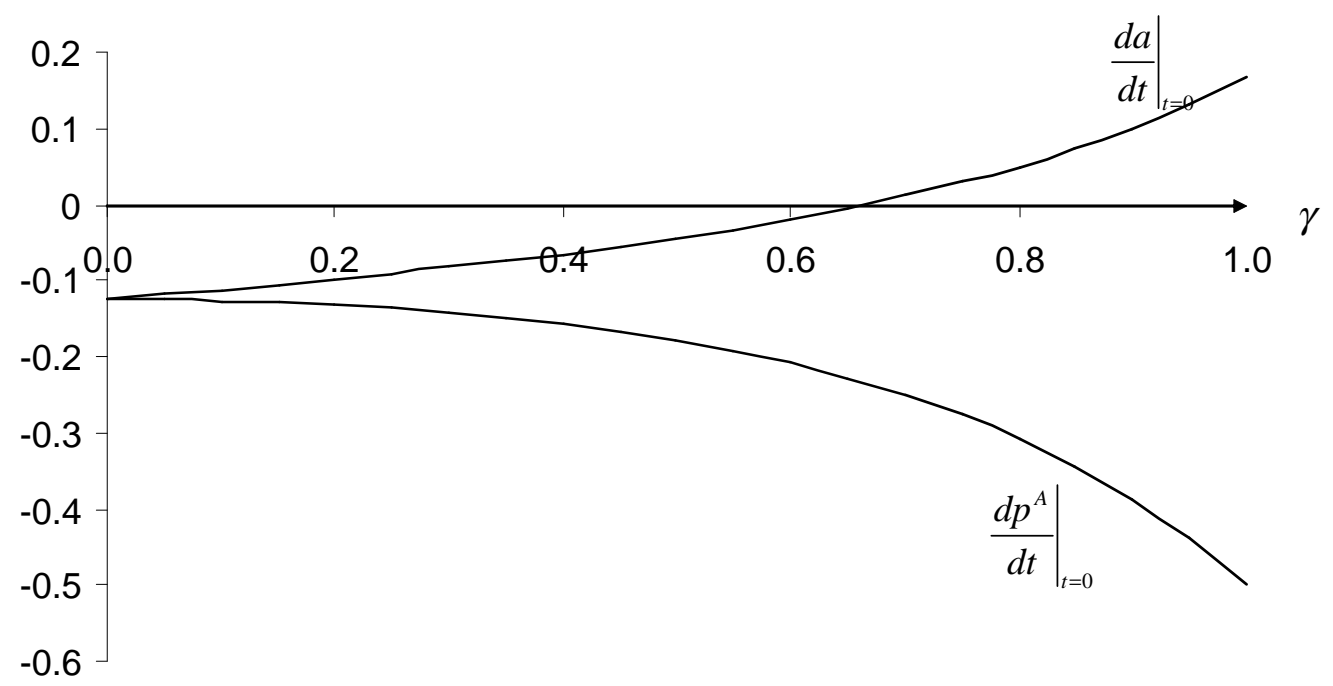


Figure 4: Taxing ads. Consequences for advertising prices and sales volume.

The intuition behind the quantity changes in Figure 4 is as follows. If the consumers dislike ads, the newspaper maximizes profit by having a lower advertising volume than that which maximizes profits on the ad-side of the market. This effect is stronger the larger $\gamma$ is, such that the incentive to "underprovide" ads is more pronounced the more the consumers dislike ads. A higher tax reduces newspaper sales, and thus increases the marginal profitability of selling ads when $\Pi_{a n}<0$. It follows that the media firm has stronger incentives to increase the advertising volume subsequent to a higher VAT on ads the larger $\gamma$ is. ${ }^{13}$ This explains why $d a / d t>0$ for sufficiently high values of $\gamma$.

Also in this example newspaper readers are adversely affected by a tax on ads, but interestingly the advertisers might benefit. This is true if $d a / d t>0$. It can further be shown that

$$
\left.\frac{d W}{d t}\right|_{t=0}=-\frac{16-30 \gamma+15 \gamma^{2}-4 \gamma^{3}}{2 D_{2}^{2}(2-\gamma)}
$$

is positive for $\gamma \in(0.77,1.0)$. For sufficiently high values of $\gamma$ we thus find that a small tax on ads increases welfare. However, this is not because the tax leads to reduced output of the good which imposes a negative externality, but on the contrary because output of that good increases. This turns standard insight from welfare analysis upside-down.

\subsection{Duopoly}

If $h>0$ the media firms compete in the advertising market (but not in the reader market, since we have set $s=0$ ). In the Appendix we show that newspaper sales fall $(d n / d t<0)$ and newspaper prices increase $\left(d p^{N} / d t>0\right)$ subsequent to a higher tax

\footnotetext{
${ }^{13}$ Mathematically, this can be seen by using equation (7) to find $\left.\Pi_{a n}\right|_{t=0}=p_{n}^{A}-\gamma-k_{a n}$. Since $\left.d \Pi_{a n}\right|_{t=0} / d \gamma<0$, a given reduction of newspaper sales leads to a larger increase in the marginal profitability of selling ads the higher $\gamma$ is.
} 
on ads for all $h \in[0,1]$. These responses are the opposite of those we would have in a one-sided market, as noted in Remark 2. The responses in the advertising side of the market are more ambiguous, and depend on the value of $h$. In particular, for $h=0$ we found that it is optimal for the newspapers to sell more ads if the tax rate on ads increases and $\gamma>2 / 3$. The same is not necessarily true if the newspapers compete in the advertising market. The reason for this is that the larger $h$ is, the less market power each newspaper will have in the advertising market, and the less profitable it is to sell more advertising space if the tax rate on ads increases. In Figure 5 we have assumed that $\gamma=4 / 5$. At $h=0$ we therefore have $d a / d t>0$, but if the competitive pressure in the advertising market becomes sufficiently strong $(h>14 / 45 \approx 0.3$ ) each newspaper will optimally respond with $d a / d t<0$. This in turn implies that the tendency to reduce the advertising price subsequent to the tax increase is less pronounced the larger is $h$.

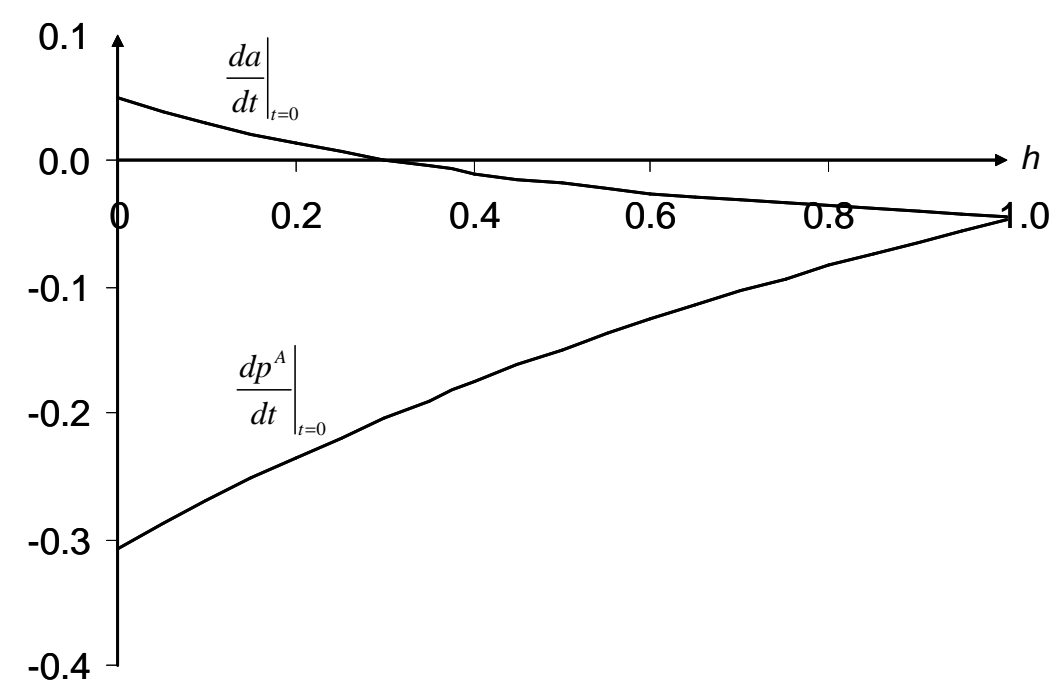

Figure 5: Competition and tax responses on the ad-side.

\section{Conclusion}

In this paper we have made use of recent advances in the theory of Industrial Organization to analyze how a tax on advertising may work. The starting point of the 
analysis is that readers/viewers perceive ads as a nuisance. Standard theory would in this case prescribe a tax on ads that makes the firms internalize the negative externalities. However, standard theory neglects the linkages that exist between the firms' customer groups. Including these linkages in the analysis, we find that a tax on ads may be counterproductive. First, it is not obvious that the advertising volume will fall. Indeed, the opposite may happen if media consumers have sufficiently strong negative attitudes towards ads. Second, even if the advertising volume should fall, the tax may have negative welfare effects. In particular, a tax on ads will reduce the media firms' incentives to make high advertising revenue by setting low consumer prices (so as to attract large audiences). We have thus identified a number of situations in which the consumers will be negatively affected by such a tax. This serves to show how important it is to understand the business model of platform firms. Tax policy does not work in a conventional way in two-sided markets.

In our analysis we have abstracted from taxation on the consumer side of the market (most European countries do for instance have VAT on consumer payments to TV channels, and some have VAT on newspaper sales). This is an innocent abstraction as long as we only consider possible corrective rationales for taxing ads. However, in policy analysis where governments also have fiscal motives for taxing ads it might be important to include tax effects on the consumer side. The reason is that it is a-priori ambiguous what will happen to tax revenue on this side of the market if the media firms' response to a tax on ads is to raise the consumer price and reduce output. In Europe, the higher price would have a positive effect on VAT revenue from the consumers, while the lower output would have a negative effect. This ambiguity should clearly also be taken into account in the discussion of including advertising services in the US sales tax system. ${ }^{14}$

\footnotetext{
${ }^{14}$ US state legislators repeatedly discuss and implement an ad tax. See the webpage by the American Advertising Federation (http://www.aaf.org/ -> government affairs) for more information.
} 


\section{Appendix}

\subsection{Calculation of Example 1}

Define $D_{1} \equiv 3\left(8(1-s)+s^{2}\right) \gamma-4\left(\gamma^{2}+(1+t)^{-2}\right)(1+t)(1-s)$. Using equations (11), (13) and (14) we find $\frac{\partial^{2} \Pi_{1}}{\partial n_{1}^{2}}<0, \frac{\partial^{2} \Pi_{1}}{\partial a_{1}^{2}}<0$ and

$$
H \equiv\left(\frac{\partial^{2} \Pi_{1}}{\partial n_{1}^{2}}\right)\left(\frac{\partial^{2} \Pi_{1}}{\partial a_{1}^{2}}\right)-\left(\frac{\partial^{2} \Pi_{1}}{\partial n_{1} \partial a_{1}}\right)^{2}=\frac{D_{1}+\gamma s^{2}}{4(1-s)(1+t)}
$$

A sufficient condition for $H$ to be positive, and thus for the second-order conditions to holds, is that $D_{1}>0$.

Inserting for (11) and (13) into (16) we have

$$
\begin{aligned}
p^{N} & =\frac{\gamma\left(12-14 s+3 s^{2}\right)(t+1)-4(1-s)}{D_{1}(1+t)} \text { and } \\
p^{A} & =2 \gamma \frac{2-s+2 \gamma(t+1)(1-s)}{D_{1}} .
\end{aligned}
$$

From (27) we find

$$
\left.\frac{d p^{N}}{d t}\right|_{t=0}=4 \gamma(1-s) \frac{4(1-s)(3-2 \gamma)+12(1-s) \gamma^{2}+2 s\left(1-\gamma^{2}\right)+3 s^{2} \gamma^{2}}{D_{1}^{2}}>0
$$

and

$$
\left.\frac{d p^{A}}{d t}\right|_{t=0}=-4 \gamma(1-s) \frac{4\left(2 \gamma-7 \gamma^{2}+1\right)-3 s^{2} \gamma^{2}-\left(8 \gamma+2-26 \gamma^{2}\right) s}{D_{1}^{2}} \gtreqless 0 .
$$

The newspaper price is thus increasing in the tax on ads, while the price response on ads is ambiguous. The upward-sloping curve in Figure 3 is found by setting $\left.\frac{d p^{A}}{d t}\right|_{t=0}=0$.

Note from (27) that both $p^{A}$ and $p^{N}$ are non-negative for $s=t=0$ iff $\gamma \in$ $[1 / 3,1] \cdot Q \cdot E \cdot D$. 


\subsection{Example 2: One sided markets}

With one-sided markets and $s=0$ we have $p_{i}^{N}=1-n_{i}$ and $p_{i}^{A}=1-a_{i}-h a_{j}$.

Solving $\left\{a_{i}, n_{i}\right\}=\Pi_{i}$ simultaneously for the two firms we find (omitting subscripts):

$$
a=\frac{3-t}{2(3-t+2 h)} \text { and } n=\frac{h}{2(3-t+2 h)} .
$$

This yields the following quantity responses subsequent to a tax increase:

$$
\frac{d a}{d t}=-\frac{h}{(3-t+2 h)^{2}}<0 \text { and } \frac{d n}{d t}=\frac{h}{2(3-t+2 h)^{2}}>0
$$

By inserting for (28) into the demand functions we further find

$$
\frac{d p^{A}}{\partial t}=h \frac{1+h}{(3-t+2 h)^{2}}>0 \text { and } \frac{d p^{N}}{d t}=-\frac{h}{2(3-t+2 h)^{2}}<0 .
$$

Q.E.D.

\subsection{Proof of Proposition 3}

Note that $H \equiv \Pi_{a a} \Pi_{n n}-\Pi_{a n}^{2}>0$ which, when $\Pi_{a n}<0$, implies

$$
\frac{\Pi_{a a}}{\Pi_{a n}}>\frac{\Pi_{a n}}{\Pi_{n n}}>0 .
$$

Rearranging both derivatives in (21), while using the above inequality, proves both statements in Proposition 3. Q.E.D.

\subsection{Calculation of Example 2}

Define $D_{2}=2(2+h)(1+t)-(\gamma(1+t)+t)^{2}$. Using equations (14), (11), and $(23)$ we find $\frac{\partial^{2} \Pi_{1}}{\partial n_{1}^{2}}<0, \frac{\partial^{2} \Pi_{1}}{\partial a_{1}^{2}}<0$ and

$$
H \equiv\left(\frac{\partial^{2} \Pi_{1}}{\partial n_{1}^{2}}\right)\left(\frac{\partial^{2} \Pi_{1}}{\partial a_{1}^{2}}\right)-\left(\frac{\partial^{2} \Pi_{1}}{\partial n_{1} \partial a_{1}}\right)^{2}=\frac{D_{2}-2 h(1+t)}{4(1-s)(1+t)}
$$

A sufficient condition for $H$ to be positive, and thus for the second-order conditions to hold, is that $D_{2}-2 h(1+t)>0$. This is ensured in the numerical example. 
From (25) we have the following quantity responses to a higher VAT on ads:

$$
\begin{aligned}
\left.\frac{d a}{d t}\right|_{t=0} & =\frac{3 \gamma-2}{2 D_{2}^{2}(\gamma+2)^{-1}}-\frac{2 h(\gamma+1)}{2 D_{2}^{2}} \text { and } \\
\left.\frac{d n}{d t}\right|_{t=0} & =-\frac{2-2 \gamma+\gamma^{2}}{D_{2}^{2}(\gamma+2)^{-1}}-\frac{h\left(5-(\gamma+1)^{2}\right)}{2 D_{2}^{2}} .
\end{aligned}
$$

Inserting for the equilibrium quantities into the demand functions and differentiating we further have:

$$
\begin{aligned}
\left.\frac{d p^{N}}{d t}\right|_{t=0} & =\frac{4-2 \gamma-\gamma^{2}}{2 D_{2}^{2}(\gamma+2)^{-1}}+\frac{\gamma^{2}+4}{2 D_{2}^{2}} h \text { and } \\
\left.\frac{d p^{A}}{d t}\right|_{t=0} & =-\frac{2-\gamma+2 \gamma^{2}}{2 D_{2}^{2}(\gamma+2)^{-1}}+\frac{h(\gamma+1)(h-\gamma+1)}{D_{2}^{2}} .
\end{aligned}
$$

Q.E.D.

\section{References}

[1] Allen, L., L. Eagle, and L. Rose (2002), Economic Implications of a Tax on TV Advertising: The New Zealand Case, Marketing Bulletin, 13, Article 4.

[2] ANA (2005), ANA Compendium of Legislative, Regulatory and Legal Issues 2004, Association of National Advertisers, New York.

[3] Anderson, S. and J. Gabszewicz (2006): The Media and Advertising: A Tale of Two-Sided Markets. In Handbook of the Economics of Art and Culture, pp 567-614, Elsevier.

[4] Armstrong, M. (2006), Competition in Two-Sided Markets, Rand Journal of Economics, 37, 668-691.

[5] Caillaud, B. and B. Jullien (2001), Competing Cybermediaries, European Economic Review, 45, 797-808.

[6] Caillaud, B. and B. Jullien (2003), Chicken and Egg: Competition Among Intermediation Service Providers, Rand Journal of Economics, 34, 309-328. 
[7] Danahar, P. (1995), What Happens to Television Ratings During Television Commercials?, Journal of Advertising Research 35, 37-48.

[8] Evans, D. S. (2003), Some Empirical Aspects of Multi-Sided Platform Industries, Review of Network Economics, 2 , 191 - 209.

[9] Fullerton, D. and G.E. Metcalf, (2002), Tax Incidence, in: A. Auerbach and M. Feldstein (eds.), Handbook of Public Economics, vol. 4, 1787-1872 (NorthHolland, Amsterdam).

[10] Gabszewicz, J. J., D. Laussel and N. Sonnac (2004), Attitudes Towards Advertising and Price Competition in the Press Industry", in: V.A. Ginsburgh (ed.): Economics of Art and Culture, Elsevier, pp. 61-74.

[11] Godes, D., E. Ofek and M. Sarvary (2008), Content vs. Advertising: The Impact of Competition on Media Firm Strategy, Marketing Science, forthcoming.

[12] Kind, H.J., T. Nilssen, and L. Sørgard (2007), Competition for Viewers and Advertisers in a TV Oligopoly, Journal of Media Economics, 20(3); 211-233.

[13] Kind, H.J., M. Koethenbuerger, and G. Schjelderup (2008), EfficiencyEnhancing Taxation in Two-Sided Markets, Journal of Public Economics, 92, $1531-1539$.

[14] Moriarty, S. E. and S.L. Everett (1994), Commercial Breaks: A Viewing Behaviour Study", Journalism Quarterly 71, 346-355.

[15] Motta, M. (2004), Competition Policy: Theory and Practice. Cambridge University Press.

[16] Rochet, J.C. and J. Tirole (2006), Two-Sided Markets: An Overview, Rand Journal of Economics, 37 , 645-667.

[17] Shubik, M. and R. Levitan (1980), Market Structure and Behavior. Harvard University Press. 
[18] Wilbur, K. C. (2008), A Two-Sided, Empirical Model of Television Advertising and Viewing Markets, Marketing Science 27, 356-378. 


\section{CESifo Working Paper Series}

for full list see www.cesifo-group.org/wp

(address: Poschingerstr. 5, 81679 Munich, Germany, office@cesifo.de)

2525 Richard Arnott and Eren Inci, The Stability of Downtown Parking and Traffic Congestion, January 2009

2526 John Whalley, Jun Yu and Shunming Zhang, Trade Retaliation in a Monetary-Trade Model, January 2009

2527 Mathias Hoffmann and Thomas Nitschka, Securitization of Mortgage Debt, Asset Prices and International Risk Sharing, January 2009

2528 Steven Brakman and Harry Garretsen, Trade and Geography: Paul Krugman and the 2008 Nobel Prize in Economics, January 2009

2529 Bas Jacobs, Dirk Schindler and Hongyan Yang, Optimal Taxation of Risky Human Capital, January 2009

2530 Annette Alstadsæter and Erik Fjærli, Neutral Taxation of Shareholder Income? Corporate Responses to an Announced Dividend Tax, January 2009

2531 Bruno S. Frey and Susanne Neckermann, Academics Appreciate Awards - A New Aspect of Incentives in Research, January 2009

2532 Nannette Lindenberg and Frank Westermann, Common Trends and Common Cycles among Interest Rates of the G7-Countries, January 2009

2533 Erkki Koskela and Jan König, The Role of Profit Sharing in a Dual Labour Market with Flexible Outsourcing, January 2009

2534 Tomasz Michalak, Jacob Engwerda and Joseph Plasmans, Strategic Interactions between Fiscal and Monetary Authorities in a Multi-Country New-Keynesian Model of a Monetary Union, January 2009

2535 Michael Overesch and Johannes Rincke, What Drives Corporate Tax Rates Down? A Reassessment of Globalization, Tax Competition, and Dynamic Adjustment to Shocks, February 2009

2536 Xenia Matschke and Anja Schöttner, Antidumping as Strategic Trade Policy Under Asymmetric Information, February 2009

2537 John Whalley, Weimin Zhou and Xiaopeng An, Chinese Experience with Global 3G Standard-Setting, February 2009

2538 Claus Thustrup Kreiner and Nicolaj Verdelin, Optimal Provision of Public Goods: A Synthesis, February 2009 
2539 Jerome L. Stein, Application of Stochastic Optimal Control to Financial Market Debt Crises, February 2009

2540 Lars P. Feld and Jost H. Heckemeyer, FDI and Taxation: A Meta-Study, February 2009

2541 Philipp C. Bauer and Regina T. Riphahn, Age at School Entry and Intergenerational Educational Mobility, February 2009

2542 Thomas Eichner and Rüdiger Pethig, Carbon Leakage, the Green Paradox and Perfect Future Markets, February 2009

2543 M. Hashem Pesaran, Andreas Pick and Allan Timmermann, Variable Selection and Inference for Multi-period Forecasting Problems, February 2009

2544 Mathias Hoffmann and Iryna Shcherbakova, Consumption Risk Sharing over the Business Cycle: the Role of Small Firms' Access to Credit Markets, February 2009

2545 John Beirne, Guglielmo Maria Caporale, Marianne Schulze-Ghattas and Nicola Spagnolo, Volatility Spillovers and Contagion from Mature to Emerging Stock Markets, February 2009

2546 Ali Bayar and Bram Smeets, Economic and Political Determinants of Budget Deficits in the European Union: A Dynamic Random Coefficient Approach, February 2009

2547 Jan K. Brueckner and Anming Zhang, Airline Emission Charges: Effects on Airfares, Service Quality, and Aircraft Design, February 2009

2548 Dolores Messer and Stefan C. Wolter, Money Matters - Evidence from a Large-Scale Randomized Field Experiment with Vouchers for Adult Training, February 2009

2549 Johannes Rincke and Christian Traxler, Deterrence through Word of Mouth, February 2009

2550 Gabriella Legrenzi, Asymmetric and Non-Linear Adjustments in Local Fiscal Policy, February 2009

2551 Bruno S. Frey, David A. Savage and Benno Torgler, Surviving the Titanic Disaster: Economic, Natural and Social Determinants, February 2009

2552 Per Engström, Patrik Hesselius and Bertil Holmlund, Vacancy Referrals, Job Search, and the Duration of Unemployment: A Randomized Experiment, February 2009

2553 Giorgio Bellettini, Carlotta Berti Ceroni and Giovanni Prarolo, Political Persistence, Connections and Economic Growth, February 2009

2554 Steinar Holden and Fredrik Wulfsberg, Wage Rigidity, Institutions, and Inflation, February 2009

2555 Alexander Haupt and Tim Krieger, The Role of Mobility in Tax and Subsidy Competition, February 2009 
2556 Harald Badinger and Peter Egger, Estimation of Higher-Order Spatial Autoregressive Panel Data Error Component Models, February 2009

2557 Christian Keuschnigg, Corporate Taxation and the Welfare State, February 2009

2558 Marcel Gérard, Hubert Jayet and Sonia Paty, Tax Interactions among Belgian Municipalities: Does Language Matter?, February 2009

2559 António Afonso and Christophe Rault, Budgetary and External Imbalances Relationship: A Panel Data Diagnostic, February 2009

2560 Stefan Krasa and Mattias Polborn, Political Competition between Differentiated Candidates, February 2009

2561 Carsten Hefeker, Taxation, Corruption and the Exchange Rate Regime, February 2009

2562 Jiahua Che and Gerald Willmann, The Economics of a Multilateral Investment Agreement, February 2009

2563 Scott Alan Carson, Demographic, Residential, and Socioeconomic Effects on the Distribution of $19^{\text {th }}$ Century US White Statures, February 2009

2564 Philipp Harms, Oliver Lorz and Dieter Urban, Offshoring along the Production Chain, February 2009

2565 Patricia Apps, Ngo Van Long and Ray Rees, Optimal Piecewise Linear Income Taxation, February 2009

2566 John Whalley and Shunming Zhang, On the Arbitrariness of Consumption, February 2009

2567 Marie-Louise Leroux, Endogenous Differential Mortality, Non-Contractible Effort and Non Linear Taxation, March 2009

2568 Joanna Bęza-Bojanowska and Ronald MacDonald, The Behavioural Zloty/Euro Equilibrium Exchange Rate, March 2009

2569 Bart Cockx and Matteo Picchio, Are Short-Lived Jobs Stepping Stones to Long-Lasting Jobs?, March 2009

2570 David Card, Jochen Kluve and Andrea Weber, Active Labor Market Policy Evaluations: A Meta-analysis, March 2009

2571 Frederick van der Ploeg and Anthony J. Venables, Harnessing Windfall Revenues: Optimal Policies for Resource-Rich Developing Economies, March 2009

2572 Ondřej Schneider, Reforming Pensions in Europe: Economic Fundamentals and Political Factors, March 2009 
2573 Jo Thori Lind, Karl Ove Moene and Fredrik Willumsen, Opium for the Masses? Conflict-Induced Narcotics Production in Afghanistan, March 2009

2574 Silvia Marchesi, Laura Sabani and Axel Dreher, Agency and Communication in IMF Conditional Lending: Theory and Empirical Evidence, March 2009

2575 Carlo Altavilla and Matteo Ciccarelli, The Effects of Monetary Policy on Unemployment Dynamics under Model Uncertainty - Evidence from the US and the Euro Area, March 2009

2576 Falko Fecht, Kjell G. Nyborg and Jörg Rocholl, The Price of Liquidity: Bank Characteristics and Market Conditions, March 2009

2577 Giorgio Bellettini and Filippo Taddei, Real Estate Prices and the Importance of Bequest Taxation, March 2009

2578 Annette Bergemann and Regina T. Riphahn, Female Labor Supply and Parental Leave Benefits - The Causal Effect of Paying Higher Transfers for a Shorter Period of Time, March 2009

2579 Thomas Eichner and Rüdiger Pethig, EU-Type Carbon Emissions Trade and the Distributional Impact of Overlapping Emissions Taxes, March 2009

2580 Antonios Antypas, Guglielmo Maria Caporale, Nikolaos Kourogenis and Nikitas Pittis, Selectivity, Market Timing and the Morningstar Star-Rating System, March 2009

2581 António Afonso and Christophe Rault, Bootstrap Panel Granger-Causality between Government Budget and External Deficits for the EU, March 2009

2582 Bernd Süssmuth, Malte Heyne and Wolfgang Maennig, Induced Civic Pride and Integration, March 2009

2583 Martin Peitz and Markus Reisinger, Indirect Taxation in Vertical Oligopoly, March 2009

2584 Petra M. Geraats, Trends in Monetary Policy Transparency, March 2009

2585 Johannes Abeler, Armin Falk, Lorenz Götte and David Huffman, Reference Points and Effort Provision, March 2009

2586 Wolfram F. Richter, Taxing Education in Ramsey’s Tradition, March 2009

2587 Yin-Wong Cheung, Menzie D. Chinn and Eiji Fujii, China's Current Account and Exchange Rate, March 2009

2588 Alexander Haupt and Silke Uebelmesser, Voting on Labour-Market Integration and Education Policy when Citizens Differ in Mobility and Ability, March 2009

2589 Hans Jarle Kind, Marko Koethenbuerger and Guttorm Schjelderup, Should UtilityReducing Media Advertising be Taxed?, March 2009 